\title{
Nova espécie de Scolecura (Araneae, Linyphiidae) do sul do Brasil ${ }^{3}$
}

\author{
Everton Nei Lopes Rodrigues ${ }^{1,2}$
}

1. Programa de Pós-Graduação em Biologia Animal, Departamento de Zoologia, Instituto de Biociências, Universidade Federal do Rio Grande do Sul, Av. Bento Gonçalves, 9500, Bloco IV, Prédio 43435, 91501-970 Porto Alegre, RS, Brasil. (enlrodrigues@yahoo.com.br). 2. Bolsista do CNPq.

3. Trabalho realizado no Museu de Ciências Naturais, Fundação Zoobotânica do Rio Grande do Sul.

ABSTRACT. New species of Scolecura (Araneae, Linyphiidae) from Southern Brazil. Scolecura cambara sp. nov. from states of Rio Grande do Sul, Santa Catarina and Paraná is described and illustrated.

KEYWORDS. Erigoninae, Scolecura, Neotropical, taxonomy.

RESUMO. Scolecura cambara sp. nov. dos Estados do Rio Grande do Sul, Santa Catarina e Paraná é descrita e ilustrada.

PALAVRAS-CHAVE. Erigoninae, Scolecura, Neotropical, taxonomia.

O gênero Scolecura compreende aranhas exclusivamente neotropicais, tendo sido proposto por Millidge (1991) que designou como espécie-tipo Scolecura cognata Millidge, 1991, descrita para a Colômbia. Além desta, outras duas espécies são conhecidas, S. propinqua Millidge, 1991, da Argentina e S. parilis Millidge, 1991, do Brasil. São caracterizadas, principalmente, pelo palpo do macho com paracímbio bem desenvolvido, apófise suprategular larga e complexa e epígino da fêmea ligeiramente esclerotinizado, com borda posterior sulcada longitudinalmente, onde se localizam dorsalmente as aberturas genitais (MILLIDGE, 1991).

Neste trabalho é descrita uma nova espécie cujo material foi depositado na coleção aracnológica do Museu de Ciências Naturais, Fundação Zoobotânica do Rio Grande do Sul, Porto Alegre (MCN; E. H. Buckup). A posição da tricobótria no metatarso da perna I (TmI) foi calculada conforme MiLLIDGE (1980). Descrições seguem Millidge $(1985,1991)$. O estudo das estruturas internas da genitália da fêmea foi realizado mergulhando o epígino em óleo de cravo. Medidas são apresentadas em milímetros (mm).

\section{Scolecura cambara sp. nov.}

(Figs. 1-10)

Material-tipo. Holótipo ơ, BRASIL, Rio Grande do Sul: Cambará do Sul (Projeto Cambará), 25.XI.1993, A. B. Bonaldo \& L. A. Moura col., coletados com peneira de solo (MCN 24286). Parátipos: + , mesma localidade, data e coletores do holótipo (MCN 39099); o', , Vacaria, 12.X.1994, A. B. Bonaldo \& L. A. Moura col. (MCN 26629); 2 o', 3 क, Palmares do Sul (Ilha Grande, Lagoa do Casamento, 30²1'36'S, 50³7'46”W), 10.IV.2003, Equipe PROBIO col., serapilheira (MCN 35501); O', 2 ㅇ, Barra do Ribeiro (Fazenda Boa Vista), 13.V.2003, Equipe PROBIO col. (MCN 35931).

Etimologia. Epíteto alusivo à localidade-tipo.

Diagnose. O palpo do macho de Scolecura cambara assemelha-se ao de S. propinqua Millidge, 1991
(MILLIDGE, 1991, figs. 486-489) por apresentar em comum êmbolo com percurso da porção distal seguindo próximo ao ápice da apófise suprategular (Figs. 3, 4), mas difere pela apófise suprategular com área distal mais alongada e bifurcada (Figs. 3, 6), subtégulo menor (Figs. 3, 5) e apófise tibial retrolateral alongada, com pequena depressão na borda da região distal (Fig. 3). Paracímbio maior que em S. cognata Millidge, 1991 (MilLIDGE, 1991, figs. 477-481) e sobre a apófise tibial. Fêmea com epígino similar ao de S. propinqua Millidge, 1991 (Millidge, 1991, figs. 490-492) e S. parilis Millidge, 1991 (Millidge, 1991, figs. 493-495) por compartilhar a borda posterior sulcada longitudinalmente, distinguindo-se por serem mais separadas entre si e pelas espermatecas mais alongadas (Fig. 9). A trajetória dos ductos copulatórios (Fig. 10) diferencia-se por seguir um trajeto sinuoso, fazendo uma volta na região mediana e não um percurso retilíneo como nas outras espécies.

Descrição. Holótipo ơ Comprimento total 1,72. Carapaça, comprimento 0,82; largura 0,60; altura 0,27. Clípeo, altura 0,15. Esterno, comprimento 0,50; largura 0,40. Abdômen, comprimento 0,89; largura 0,52; altura 0,44. Fórmula das pernas $1 / 4 / 2 / 3$. Comprimento $1 / 2 / 3 / 4$ : fêmures $0,70 / 0,57 / 0,50 / 0,65$; patelas $0,22 / 0,15 / 0,17 / 0,17$; tíbias $0,62 /$ $0,55 / 0,40 / 0,62$; metatarsos $0,55 / 0,50 / 0,40 / 0,50$; tarsos $0,42 /$ $0,35 / 0,30 / 0,37$. Total 2,51/2,12/1,77/2,31. Posição da tricobótria no metatarso da perna I (TmI) 0,27. Carapaça castanho-avermelhada com bordas mais escuras (Fig. 1); área ocular enegrecida, mais larga do que longa. Fila ocular anterior $0,27 \mathrm{e}$ posterior 0,28 . OLA maiores que os demais e OMA menos desenvolvidos. Esterno castanhoamarelado com bordas castanho-escuras (Fig. 2); enditos castanho-amarelados e quelíceras castanho-avermelhadas. Pernas com fêmur castanho-avermelhado e demais artículos amarelo-claros. Abdômen dorsalmente amarelo-claro com laterais e região posterior castanho-escuras. Ventre amarelo-claro com área em torno das fiandeiras castanhoescura. Palpo com apófise tibial prolateral pouco 

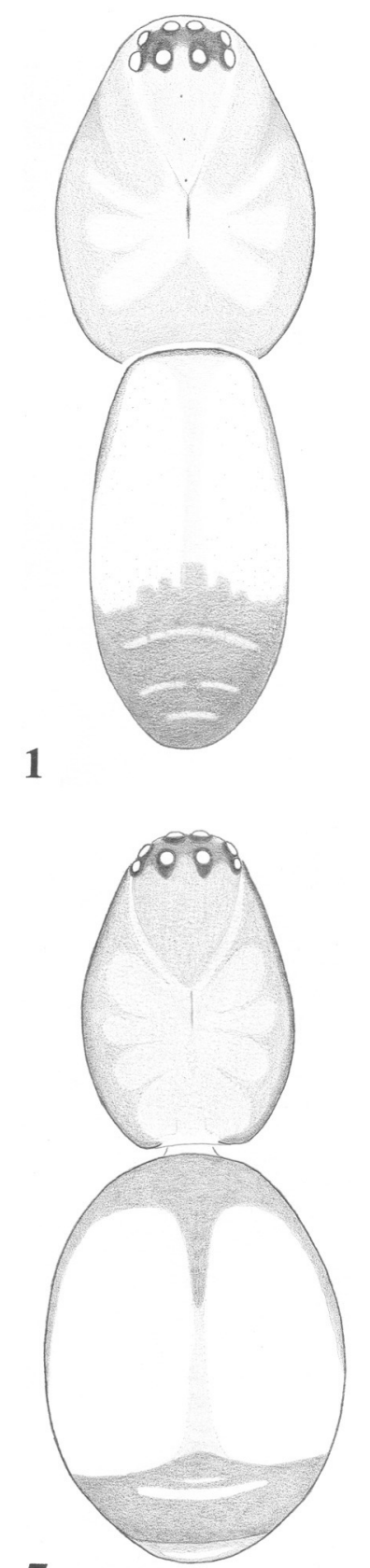

7

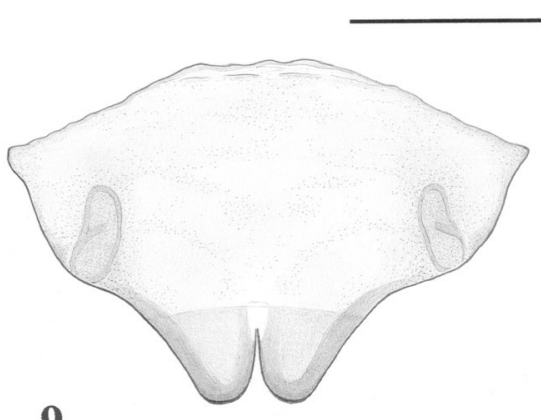

9

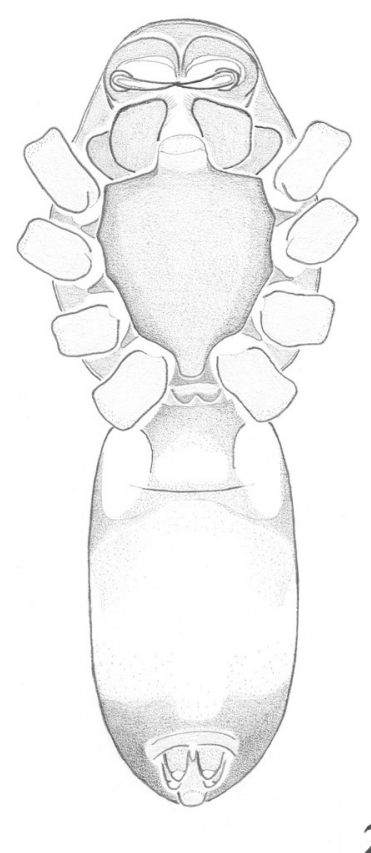

2

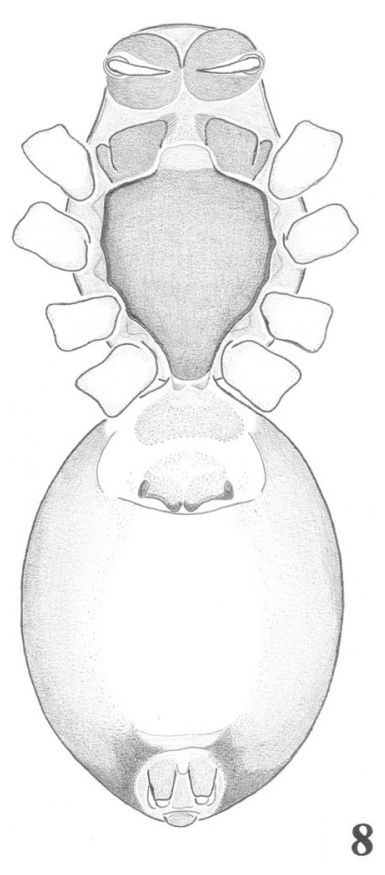

8

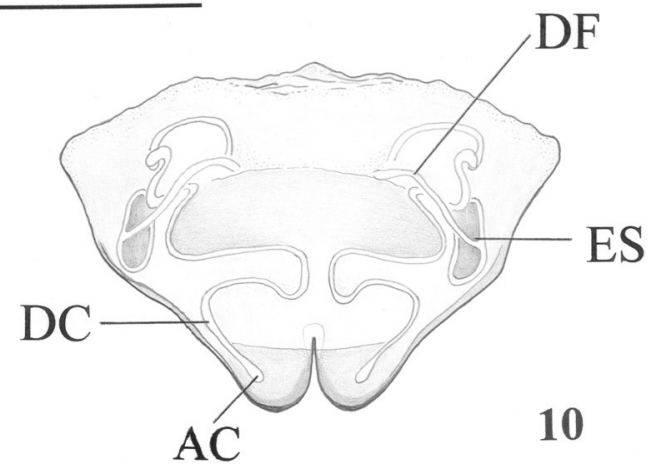

$\mathrm{AC}$

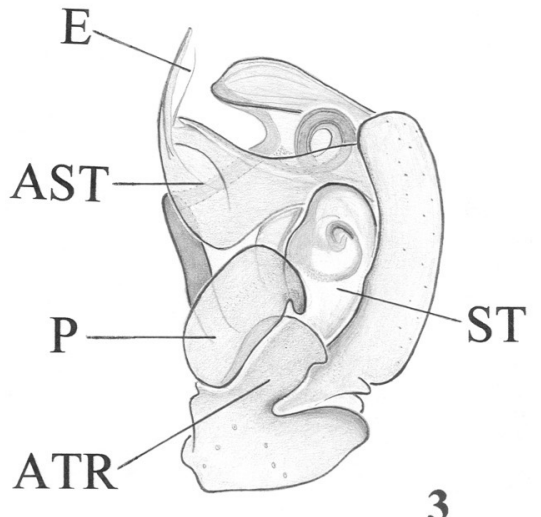

3
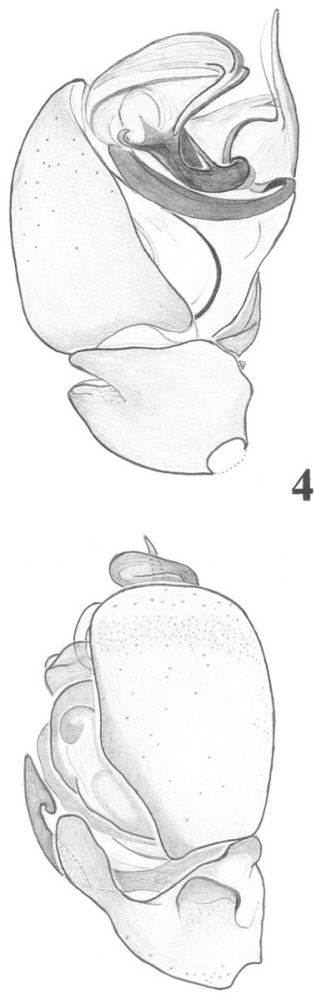

5

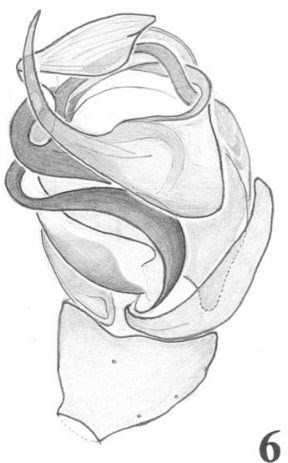

6

Figs. 1-10. Scolecura cambara sp. nov. 1, 2, macho: 1, dorsal; 2, ventral. 3-6, palpo do macho: 3, ectal; 4, mesal; 5, dorsal; 6, ventral. 7, 8, fêmea: 7, dorsal; 8, ventral. 9, 10, epígino: 9, ventral; 10, dorsal (AC, abertura de copulação; AST, apófise suprategular; ATR, apófise tibial retrolateral; DC, ducto de copulação; DF, ducto de fertilização; E, êmbolo; ES, espermateca; P, paracímbio; ST, subtégulo). Barras: Figs. 1, 2, 7, 8, 0,5 mm; Figs. 3-6, 9, 10, 0,3 mm. 
desenvolvida e apófise suprategular na porção distal em forma de gancho (Figs. 3, 6).

Parátipo 9 (MCN 39099). Comprimento total 1,90. Carapaça, comprimento 0,80; largura 0,57; altura 0,27. Clípeo, altura 0,12. Esterno, comprimento 0,50; largura 0,40 . Abdômen, comprimento 1,10 ; largura 0,77 ; altura 0,80 . Fórmula das pernas 1/4/2/3. Comprimento 1/2/3/4: fêmures 0,70/0,60/0,50/0,70; patelas 0,22/0,20/0,17/0,20; tíbias 0,62/ $0,52 / 0,44 / 0,65$; metatarsos 0,52/0,50/0,42/0,52; tarsos 0,44/ $0,37 / 0,32 / 0,37$. Total 2,53/2,19/1,85/2,44. Posição da tricobótria no metatarso da perna I (TmI) 0,30. Carapaça castanho-escura com bordas e área ocular enegrecidas (Fig. 7). Fila ocular anterior 0,27 e posterior 0,31. OLA maiores e OMA os menores. Esterno (Fig. 8) castanhoescuro, enditos e quelíceras castanho-avermelhados, com tonalidade mais escura que no macho. Pernas com todos os artículos amarelo-claros. Dorso do abdômen amareloclaro com região anterior, posterior, laterais e uma mancha longitudinal castanho-escuras. Ventre amarelado com região em torno das fiandeiras castanho-escura. Epígino com ductos de copulação longos, seguindo um percurso irregular até as espermatecas; aberturas copulatórias dorsalmente na área posterior das bordas da placa do epígino e ductos de fertilização com origem nas espermatecas (Fig. 10).

Material examinado. BRASIL, Paraná: Capitão Leônidas Marques (Salto Caxias, Rio Iguaçu), ơ , 8 \&, 20-28.III.1993, A. B. Bonaldo col., peneira de solo e pitfall trap (MCN 23473, 23480).

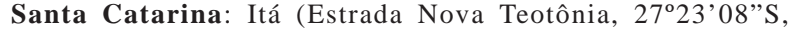
5109'19”W), O’, 01.II.1996, A. B. Bonaldo \& R. P. da Rocha col. (MCN 27179). Rio Grande do Sul: Cambará do Sul (Projeto Cambará), 7 đ’, 11-13.IV.1994, A. B. Bonaldo \& L. A Moura col., folhiço (MCN 25516); Canela (Barragem Canastra), O $O^{7}, 20$ 22.III.2001, R. Ott col., pitfall trap (MCN 33753); São Francisco de Paula (Barragem Passo do Inferno), $20^{7}, 20-22 . I I I .2001, R$. Ott col., pitfall trap (MCN 33767); Santa Maria (Sarandi), ơ 30.VII.2000, L. Indrusiak col., serapilheira (MCN 33896); Triunfo (Parque Copesul de Proteção Ambiental), 2 †, 20.XII.2000, M. P. Barros col., serapilheira (MCN 33546), $200^{7}, 10$, 28.VIII.2001-17.IX.2002, R. Ott col., pitfall trap, ecletor de solo e extrator de Winkler (MCN 34241, 34426, 34446, 34500, 34553, 34719, 34727, 34895); Viamão (foz do arroio Itapuã, mata junto à nascente), $25 \sigma^{2}$, + , 11.IX.2001, L. E. C. Schmidt \& R. Ott col, pitfall trap (MCN 34283, 34296); Barra do Ribeiro (Fazenda Boa Vista), 2 ơ, 7 \&, 16.V.2003, Equipe PROBIO col. (MCN 35927).

Distribuição. Sul do Brasil (Paraná, Santa Catarina e Rio Grande do Sul).

Agradecimentos. À curadora da coleção aracnológica do MCN Erica H. Buckup, pelo acesso ao material e à bibliografia. À Maria Aparecida de L. Marques (MCN), ao Ricardo Ott (MCN) e aos revisores pelas sugestões apresentadas. À direção do MCN pelo uso das dependências e equipamentos. Ao CNPq pela concessão da bolsa de mestrado (Proc. 131628/2005-4).

\section{REFERÊNCIAS BIBLIOGRÁFICAS}

Millidge, A. F. 1980. The erigonine spiders of North America. Part 1. Introduction and taxonomic background (Araneae: Linyphiidae). The Journal of Arachnology 8:97-107. 1985. Some linyphiid spiders from South America (Araneae, Linyphiidae). American Museum Novitates 2836:1-78. 1991. Further linyphiid spiders (Araneae) from South

America. Bulletin of the American Museum of Natural History 205:1-199. 